\title{
Prevalence and Correlates of Physical Disability and Functional Limitation among Elderly Rural Population in Nigeria
}

\author{
I. S. Abdulraheem, ${ }^{1}$ A. R. Oladipo, ${ }^{2}$ and M. O. Amodu ${ }^{3}$ \\ ${ }^{1}$ Department of Epidemiology and Community Health, College of Medicine, University of Ilorin, 240001 Ilorin, Nigeria \\ ${ }^{2}$ Department of Epidemiology and Community Health, University of Ilorin Teaching Hospital, 240001 Ilorin, Nigeria \\ ${ }^{3}$ Department of Community Medicine, College of Medical Sciences, University of Maiduguri, 600235 Maiduguri, Nigeria
}

Correspondence should be addressed to I. S. Abdulraheem, ibroraheem@yahoo.com

Received 17 December 2010; Revised 27 February 2011; Accepted 12 April 2011

Academic Editor: Steven Hooker

Copyright (c) 2011 I. S. Abdulraheem et al. This is an open access article distributed under the Creative Commons Attribution License, which permits unrestricted use, distribution, and reproduction in any medium, provided the original work is properly cited.

Background. The number of people surviving into old age is increasing, and it has now become a global phenomenon. Studies on the prevalence and correlates of physical disability and functional limitation among elderly Nigerians are scanty. Methodology. This is a community-based cross-sectional study conducted in 3 local government areas (LGAs) in Nigeria, using a multistage sampling technique. Functional limitations of 1824 elderly persons were tested using Tinetti performance-oriented mobility assessment tool (TPOMAT) and self-reported activities of daily living (ADL). ADL disability of ten, six, and five basic items were compared. Results. The prevalence ratios (PRs) of physical disability using the ten, six, and five basic ADL items were 28.3 (95\% CI $25.2-31$. 5), 15.7 (95\% CI 13.4-19.8), and 12.1 (95\% CI 9.8-15.3), respectively, while functional limitation was 22.5 (95\% CI 18.1-24.4). Increased risk of disability was independently associated with female gender PR 3.6 (95\% CI 1.5-7.4), advanced age $\geq 75$ years; PR 22.2 (95\% CI 14.5, 36.8), arthritis PR 3.7 (95\% CI 2.6-4.6), stroke PR 4.8 (95\% CI 3.7-7.9) and diabetes PR 6.1 (95\% CI 4.3-7.1). Conclusions. The findings from this study are pointers to unmet needs of the elderly disabled Nigerians.

\section{Introduction}

The number of people surviving into old age is increasing, and it is a global phenomenon affecting developing and developed countries [1]. Information on disability is very important in responding to the care of the elderly. Disability is defined as a restriction in the ability to perform normal activities of daily living [2], and it helps to quantify the impact of disease or injury. Disability is particularly a useful concept in assessing the health of elderly people, because they have several diseases occurring simultaneously with varied severity and impacts on their daily lives. Gill and colleagues [3] have reported the powerful effects of disability on individual well-being, the need for informal help and health care, as well as long-term care needs and costs. On the basis of this, the epidemiology of elderly disability cannot be overemphasized. The process of disability represents a distinct phase in the life of many elderly persons [2]. Functional limitation is associated with loss of independence and with increased need for both formal and informal care $[4,5]$. The prevalence of physical disability in elderly persons with functional limitation are, therefore, important for policy development on care of the elderly be it formal or informal care. Contrary to the developed nations [6], most developing nations, specifically those in sub-Sahara Africa, lack reliable data to formulate policy on aging even though the populations of their elderly persons (aged 60 years and above) are increasing even more than developed nations [7].

The pattern and profile of disability that is obtained among the elderly in developed countries differs from those in developing nations. This is expected because of the difference in life expectancy. For example, life expectancy in Nigeria is currently about 48 years for elderly men and 50 years for elderly women [8]. In the developed countries, the available data suggest that life expectancy at birth was around 35 to 40 years in the mid-1700s, rose to about 45 to 50 by the mid-1800s, so that by the middle of the twentieth century, it was approximately 66 to 67 years probably because of that 
rapid improvements that began at the end of the nineteenth century [9]. Physical disability and functional limitation are common among older people [10], leading to adverse consequences such as dependency and institutionalization. Older people's ability to function independently is important, as physical disability and functional limitation have profound public health implications with increased utilization of health care and a need for supportive services and long-term care [4]. Due to economic hardship and extreme limitation of well-paid job opportunities in rural areas, most children and caregivers of the elderly have migrated to towns and cities for greener pasture thus abandoning the elderly with their disabilities. This underscores the need to study the prevalence of physical disability and functional limitation especially in a Nigerian rural underserved population of older adults.

Several studies [11] on physical disability and functional limitation have been reported in developed countries. However, data are very scanty for developing countries especially in rural Nigeria. Apart from demographic factors like female gender and increasing age $[12,13]$, social variables like smoking and alcohol consumption, low-income earning, low education, and urban dwelling have been associated with increased risk of disability among elderly persons $[12,14]$. In many respects, these correlates of disability are particularly germane to sub-Saharan Africa in general and Nigeria in particular [15]. The objective of this study is, therefore, to determine the prevalence and factors associated with physical disability and functional limitation among elderly Nigerian.

\section{Methodology}

2.1. Study Population, Research Instrument, and Methods. The study subjects were elderly rural dwellers aged 60 years and above from Abadam, Guzamala, and Mobbar local government areas (LGAs) in Borno State, North-Eastern Nigeria; and the study was conducted between March and August 2010. Elderly people who were non-Nigerians and those who were temporary residents (lived in the community less than 24 months) were excluded from the study. The study population was identified from 2006 community census list which was obtained from the LGA population census unit. Homes of the participants and primary health centers in each selected local government areas served as the venues of interview and clinical assessments, respectively. In order to reduce or avoid missed opportunity, interviews and clinical assessment were conducted three times a week. Period of interview was in the morning and evening, while the clinical assessment was between $8 \mathrm{am}$ to $4 \mathrm{pm}$ daily in the health centers.

The interview and clinical assessment were conducted by seven community health officers and three nurses mostly Kanuri indigenes that were very fluent in Kanuri and Hausa Languages and were trained as research assistants in all aspects of the study such as questionnaire administration and clinical assessment. The questionnaire was pretested in another Kanuri Community to avoid ambiguity and easy administration during the survey.
2.2. Relevant Health Related and Sociodemographic Information. Information on the following relevant health-related variables was obtained: presence of chronic conditions, depressive symptomatology, height and weight measurement, cognitive function, and presenting visual acuity. Questions about the presence of chronic diseases include have you ever been managed as a patient for diseases like hypertension, heart attack, diabetes, epilepsy, stroke, arthritis, pneumonia, and asthma? Chronic conditions were coded A, B, and C. Hypertension and heart attack belongs to code "A", diabetes belongs to code " $B$ ", while arthritis, pneumonia, and asthma were coded " $C$ ". Depressive symptomatology was assessed using the short version of the geriatric depression scale 15 item (GDS) [16]. Scores ranges from 0-15, with scores of six or more indicate depressive symptomatology. Height and weight were measured with the participants in light clothing and without shoes. Body mass index (BMI) was calculated as weight in kilogram divided by square of height in meter expressed as $\mathrm{kg} / \mathrm{m}^{2}$ in the result and table. BMI is an index, and therefore, it has no unit.

Cognitive function was assessed using the elderly cognitive assessment questionnaire (ECAQ) [17]. ECAQ has been shown to be a valid tool for assessment of cognitive impairment among older people living in developing countries [17]. ECAQ scores range from $0-10$. A score of 0 to 4 indicates probable cognitive impairment, 5 to 6 borderline, and 7 and above as normal. Visual acuity was assessed at designated primary health care centers using a standard metric Snellen chart of alphabets E type at 6 meters. Participants' self reporting or presenting visual acuity (PVA) was ascertained with wearing of habitual optical corrective glasses (spectacles). The World Health Organization [18] defines mild or moderate visual impairment as PVA of less than $6 / 18$ but equal to or better than 3/60. Blindness is defined as PVA of less than 3/60 in the better eye [18]. Mid-arm circumference wad used as a measure of malnutrition. Face-to-face interview was used to collect data on sociodemographic variables like gender, age, education level, marital status, social support, monthly income, ownership of motor vehicle, ownership of modern house, living arrangement, and ethnicity. Ethnic group was categorized as Kanuris, Fulanis, and Hausa.

2.3. Study Design and Sampling Technique. This is a population-based cross sectional study and multistage sampling technique was used. The three LGAs were purposively chosen but randomly selected using simple random sampling technique from the available rural LGAs and subjects were allocated to each LGA proportionately according to population of the elderly in the LGAs. Cluster sampling technique was used in the final selection of all participants (total sampling) in each LGA that met the inclusion criteria.

2.4. Measures of Physical Function. Two physical function measures were used in the assessment: performance-based functional limitation and self reported physical disability. The Tinetti Performance oriented mobility assessment tool (TPOMAT) was used and is a measure of functional limitation that assesses older people's gait and balance abilities $[19,20]$. In conducting the balance assessment, 
the participants were seated in hard, straight-backed, armless chairs. Participants' balance abilities were assessed by performing maneuvers such as sitting in chair, rising from chair, immediate standing balance (first three to five seconds after standing), further standing balance, balance with eyes closed, turning balance, ability to withstand displacement when slightly pushed from the sternum, neck turning, one leg standing balance, back extension, reaching up, bending down, and finally sitting down. For gait assessment, participants were asked to stand with the examiner in an obstacle-free walkway. Participants used their usual walking aid and were asked to walk down the walkway at their usual pace. Participants' gaits were observed for initiation of gait, step height, step length, step symmetry, step continuity, path deviation, trunk stability, walk stance, and turning while walking. For maneuvers such as path deviation, trunk stability, and walk stance, the examiner walked behind the participants and for others next to the participants. Participants were then asked to walk back at a "more rapid than usual but safe pace" using usual walking aids.

Level of performance of each activity was rated 0-1, where a score of 0 meant inability to perform the activity and a score of 1 meant ability to perform the activity. The maximum score for the gait component was 12 points and for the balance component it was 16 points. Participants with scores of less than 12 (for gait) or less than 16 (for balance) were defined as having performance-based functional limitation. In order to test for physical disability, the ten-item Barthel index was used. Barthel index is an assessment of patients' level of independence in activities of daily living (ADL) [21]. The ten ADL items assessed were feeding, bathing, dressing, grooming, toileting, bladder control, bowel control, transferring from bed to chair, walking, and stair climbing. For this study, the operational definition of physical disability is needing help in one or more of these ADL activities. In order to compare this study with others, physical disability was also determined using the six Katz index of independence in ADL items related to self care (feeding, dressing, bathing, toileting, transferring, and walking) $[22,23]$ and five items related to self-care (feeding, dressing, bathing, toileting, and transferring) [24].

2.5. Data and Statistical Analysis. Following collection, collation, and editing, data were entered into a computerized data base. Data were analyzed using statistical package for social sciences (SPSS) version 16. Clustering of data and sampling probability weights were taken into consideration during the analysis. In order to allow comparison with prevalence of ADL disability reported in other studies, we estimated the prevalence of ten, six, and five items ADL dependence. In this study, the prevalence for disability was also aged standardized population using the indirect standardization method for proper comparison with studies elsewhere.

Indirect standardization method was also used for comparing prevalence of physical disability and functional limitation across the three ethnic groups (Kanuris, Fulanis, and Hausa), and in this study, Kanuris group was used as the standard population. As a result of the high prevalence of physical disability and functional limitation, prevalence ratio (PR) was calculated instead of odds ratio (OR) [25]. All analyses were carried out using SPSS log binomial regression and Poisson regression with strong and reliable variance [26]. Two sets of univariate analyses were performed using chi-square tests: firstly, analysis was done to identify associations between the ten items physical disability and health related and sociodemographic variables; secondly, similar analysis was done with functional limitation. Then, multivariate Poisson regression with robust variance was performed to test which of the health-related variables and sociodemographic variables were independently associated with physical disability and functional limitation. Variables with clinical and statistical significance $(P$ value of $<.05$ in the univariate analysis) were regarded as being significant. Participants with cognitive impairment identified through scores of less than five based on the elderly cognitive assessment questionnaire (ECAQ), were removed from the analysis $(n=43)$. Individual medical conditions (such as stroke, diabetes, arthritis, etc.) were used as explanatory variables in the analysis to find out their association with disability as well as functional limitation.

2.6. Ethical Approval. Due to very high illiteracy level in the study areas, informed (verbal) consent was obtained from all participants.

\section{Results}

3.1. Response Rate. Of the 1905 questionnaires distributed to elderly people who satisfied the inclusion criteria, 1824 respondents completed the questionnaire and were also available for physical examination, giving a response rate of $95.7 \%$. Reasons for nonresponse include lack of interest $(25 \%)$, competing issues $(60 \%)$, sickness $(5 \%)$, and traveling $(10 \%)$.

3.2. Respondents Sociodemographic and Health Variables. Table 1 depicts the sociodemographic and health variables of the respondents. The age of respondents ranged from 60 to $87 \mathrm{yrs}$ (with mean age of $69 \pm 7$ years SD). Of the elderly men, $31.2 \%$ were within $60-64$ yrs age group, $28.6 \%$ were 65-69 years, $23.7 \%$ were $70-74$ yrs, and $16.5 \%$ were 70 years and above. In the elderly women category, $34.6 \%$ were within 60-64 yrs age group, $26.1 \%$ were $65-69$ years, $21.1 \%$ were $70-74$ yrs, and $18.2 \%$ were 70 years and above. There were more elderly women [977 (53.3\%)] than elderly men [847 $(46.7 \%)]$. Illiteracy level was $85 \%$ and of those that were literate, $87 \%$ had primary education and $11 \%$ had secondary education and $3 \%$ had tertiary education. Of all the elderly women, only $4.6 \%$ had secondary education, $15.3 \%$ had primary education and $80.1 \%$ had no formal education. None of the elderly women had tertiary level of education. Kanuri (84.\%) constitutes the major ethnic group, while Fulani and Hausa represent $8.8 \%$ and $7.2 \%$, respectively. Marital status of elderly men showed $86.3 \%$ married, $10.8 \%$ widowed, $1.8 \%$ divorced, and $1.1 \%$ single. Of the elderly women, $45.7 \%$ were married, $38.5 \%$ were widowed, $11.1 \%$ were divorced, and $4.7 \%$ were single.

More than four-fifth (88.4\%) of the respondents live with other family members, while $11.6 \%$ lived alone. In both 
sexes, more than two-thirds had normal cognitive function, $92.1 \%$ in elderly men and $81.2 \%$ in elderly women. Elderly women $(12.6 \%)$ are two times borderline cognitive impaired compared with elderly men (6.1\%). Also, elderly women (5.4\%) are about three times probably cognitive impaired compared with elderly men (1.8\%). More elderly women (24\%) had more than one chronic disease than elderly men $(15.5 \%)$. Elderly women $(25.1 \%)$ are slightly more depressed than elderly men $(22.7 \%)$. Elderly women $(16.4 \%)$ are also more overweight than elderly men (12.5\%). More than threequarters $(78.5 \%)$ earned less than one hundred American Dollars per month and less than $5 \%$ of the participants earned more than three hundred American Dollars per month (Table 1).

\subsection{Physical Disability and Functional Limitation Prevalence} Rate. The prevalence rates for physical disability and functional limitation are shown in Table 2. More than onequarter $(28.3 \%)$ of the respondents signified interest for assistance in at least one of the 10 ADLs in the Barthel index. The prevalence of disability based on at least one item of the six ADL scale was $15.7 \%$ and prevalence of disability based on at least one item in the five ADL scale was $12.1 \%$. The prevalence of functional limitation was $22.5 \%$. The overall prevalence of disability ( 10 items ADL, 6 items ADL, and 5 items ADL) and functional limitation increased with advancing age. The prevalence of needing help in at least one of the ten ADLs of the Barthel index increased from 11.7 in those aged $60-64$ years, to $98.9 \%$ of those aged 75 years and older (Table 2). The prevalence of functional limitation rose from $12.4 \%$ in those aged 60 to 64 years to $98.3 \%$ in the 75 years and above age group (Table 2). In all the participants, the prevalence of both self-reported physical disability and objective measurement of functional limitation was higher in elderly women than in elderly men (Table 2). Among the three ethnic groups, Kanuris had the highest prevalence of physical disability ( 10 items ADL, 6 items ADL, and 5 items ADL) compared to the Fulanis and Hausa (Figure 1).

However, the prevalence of functional limitation was almost similar across all ethnic groups. The correlations between performance-based functional limitation and selfreported physical disability among the different ethnic groups showed thus that the correlation coefficient for Kanuris, Hausas, and Fulanis were 0.52, 0.48, and 0.23, respectively. Elderly persons with levels of mid-arm circumference indicative of severe malnutrition had an increased risk of physical disability and functional limitation (Table 3). Among the four groups of monthly level of income, respondents that earned less than 100 US\$/month had the highest prevalence of physical disability (10 items ADL, 6 items ADL, and 5 items ADL). The prevalence of functional limitation rose from $0.6 \%$ in those that earned more than 300 US $\$ /$ month to $33.2 \%$ in those that earned less $100 \mathrm{US} \$$ /month.

3.4. Outcome of Sociodemographic and Health Correlates on Physical Disability and Functional Limitation. With increase in age, elderly women with low education self-reported one or more chronic diseases than their elderly men counterparts.

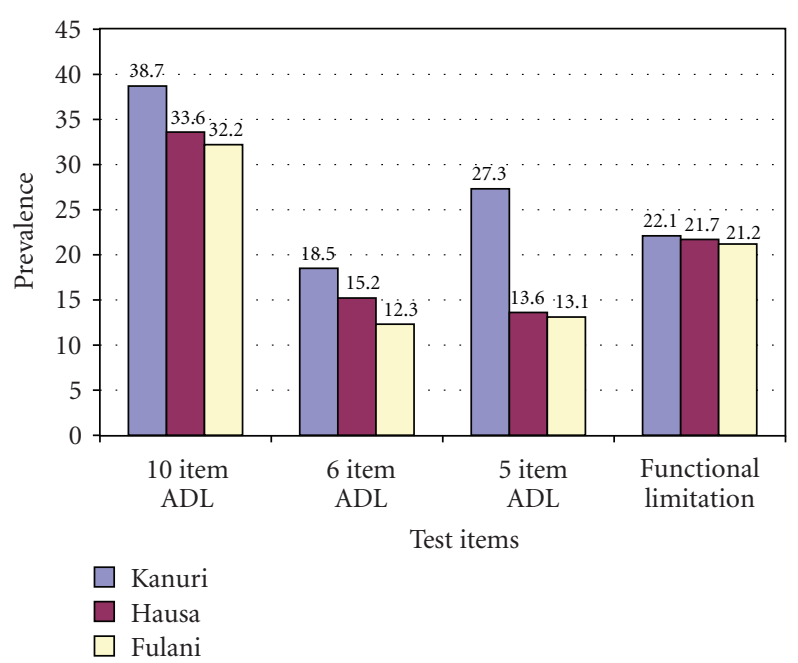

FIgURE 1: Prevalence of physical disability and functional limitation by ethic group among Nigerian rural elderly.

This study also showed that having depressive symptomatology and presence of visual impairment (mild-to-moderate blindness) were found to be more associated with physical disability. Furthermore, being at risk of isolation was associated with functional limitation (Table 4). In Table 4, all explanatory variables except ethnicity used in the univariate analysis were significantly associated with functional limitation. The multivariate associations between physical disability and functional limitation, and sociodemographic and health-related variables are shown in Table 5.

Table 5 shows a significant independent associations between physical disability and advanced age, ( $\geq 75$ years: prevalence ratio (PR) 22.2; 95\% CI 14.5-36.8), presence of diabetes (PR 6.1; 95\% CI 4.3-7.1), and visual impairment (blindness: PR 6.6; 95\% CI 3.6-11.9). The independent variables found to be associated with functional limitation include advanced age, ( $\geq 75$ years: PR 10.5 ; $95 \%$ CI 5.416.4), female gender (PR 9.3; 95\% CI 3.7-18.3), presence of arthritis (PR 5.2; 95\% CI 3.5-6.8), and having depressive symptomatology (PR 6.4; 95\% CI 4.7-9.2).

\section{Discussion}

In contrast to physical disability, functional limitation represents an outcome that is free from external factors or environmental influences. This adds clarity to the understanding of the dynamics of the pathway from disease to disability [27]. The study population was randomly selected from geographically defined rural communities, and a high response rate was recorded. The prevalence rates of physical disability for all the three ADL scales and functional limitations were less than one-third and increased with age. The increase was observed to be higher in elderly women than elderly men and among Kanuris than among Fulanis and Hausas. The increase observed among the ethnic groups was not statistically significant. Advance in age, presence of diabetes, stroke, depressive symptomatology, and visual 
TABLE 1: Respondents sociodemographic and health related variables by sex.

\begin{tabular}{|c|c|c|c|}
\hline Variables & Male frequency (\%) & Female frequency $(\%)$ & Total frequency $(\%)$ \\
\hline \multicolumn{4}{|l|}{ Age } \\
\hline $60-64$ & $265(31.2)$ & $338(34.6)$ & $603(33.1)$ \\
\hline $65-69$ & $242(28.6)$ & $255(26.1)$ & $497(27.3)$ \\
\hline $70-74$ & $201(23.7)$ & $206(21.1)$ & $407(22.3)$ \\
\hline $75 \&$ above & $139(16.5)$ & $178(18.2)$ & $317(20.3)$ \\
\hline Total & $847(100.0)$ & $977(100.0)$ & $1824(100.0)$ \\
\hline \multicolumn{4}{|l|}{ Marital status } \\
\hline Married & $730(86.3)$ & $446(45.7)$ & $1166(63.9)$ \\
\hline Widowed & $93(10.8)$ & $376(38.5)$ & $469(25.7)$ \\
\hline Divorced & $15(1.8)$ & $109(11.1)$ & $124(6.8)$ \\
\hline Single & $19(1.1)$ & $46(4.7)$ & $65(3.6)$ \\
\hline Total & $847(100.0)$ & $977(100.0)$ & $1824(100.0)$ \\
\hline \multicolumn{4}{|l|}{ Educational level } \\
\hline No formal education & $352(41.6)$ & $783(80.1)$ & $1135(62.2)$ \\
\hline Primary education & $365(43.0)$ & $149(15.3)$ & $514(28.2)$ \\
\hline Secondary education & $116(13.8)$ & $45(4.6)$ & $161(8.8)$ \\
\hline Tertiary education & $14(1.6)$ & $0(0.0)$ & $14(0.8)$ \\
\hline Total & $847(100.0)$ & $977(100.0)$ & $1824(100.0)$ \\
\hline \multicolumn{4}{|l|}{ Ethnicity } \\
\hline Kanuri & $645(76.2)$ & $818(83.7)$ & $1532(84.0)$ \\
\hline Fulani & $120(14.2)$ & $92(9.5)$ & $161(8.8)$ \\
\hline Hausa & $82(9.6)$ & $67(6.8)$ & $131(7.2)$ \\
\hline Total & $847(100.0)$ & $977(100.0)$ & $1824(100.0)$ \\
\hline \multicolumn{4}{|l|}{ Living arrangement } \\
\hline Living alone & $70(8.3)$ & $142(14.5)$ & $212(11.6)$ \\
\hline Living with others & $777(91.7)$ & $835(85.5)$ & $1612(88.4)$ \\
\hline Total & $847(100.0)$ & $977(100.0)$ & $1824(100.0)$ \\
\hline \multicolumn{4}{|l|}{ Social support status } \\
\hline Likely to be isolated & $115(13.6)$ & $216(22.2)$ & $331(18.1)$ \\
\hline Isolation not likely & $732(86.4)$ & $761(77.8)$ & $1493(81.9)$ \\
\hline Total & $847(100.0)$ & $977(100.0)$ & $1824(100.0)$ \\
\hline \multicolumn{4}{|l|}{ Cognitive status } \\
\hline Normal & $780(92.1)$ & $801(81.2)$ & $1581(86.7)$ \\
\hline Borderline cognitive impaired & $52(6.1)$ & $123(12.6)$ & $175(9.6)$ \\
\hline Probably cognitive impaired & $15(1.8)$ & $53(5.4)$ & $68(3.7)$ \\
\hline Total & $847(100.0)$ & $977(100.0)$ & $1824(100.0)$ \\
\hline \multicolumn{4}{|l|}{ Depression assessment } \\
\hline No & $655(77.3)$ & $732(74.9)$ & $1387(76.0)$ \\
\hline Yes & $192(22.7)$ & $245(25.1)$ & $437(24.0)$ \\
\hline Total & $847(100.0)$ & $977(100.0)$ & $1824(100.0)$ \\
\hline \multicolumn{4}{|l|}{$B M I\left(K g / m^{2}\right)$} \\
\hline Underweight $(<20.0)$ & $401(47.3)$ & $357(36.5)$ & $758(41.6)$ \\
\hline Normal (20.0-24.9) & $368(43.3)$ & $405(41.5)$ & $773(42.4)$ \\
\hline Overweight (25.0-29.9) & $55(6.5)$ & $163(16.7)$ & $218(11.9)$ \\
\hline Obese $(\geq 30.0)$ & $23(2.7)$ & $52(5.3)$ & $75(4.1)$ \\
\hline Total & $847(100.0)$ & $977(100.0)$ & $1824(100.0)$ \\
\hline
\end{tabular}


TABLE 1: Continued.

\begin{tabular}{|c|c|c|c|}
\hline Variables & Male frequency $(\%)$ & Female frequency (\%) & Total frequency (\%) \\
\hline \multicolumn{4}{|l|}{ Chronic disease status } \\
\hline 0 & $254(30.0)$ & $387(39.6)$ & $641(35.1)$ \\
\hline 1 & $462(54.5)$ & $535(54.8)$ & $997(54.7)$ \\
\hline$>1$ & $131(15.5)$ & $55(24.0)$ & $186(10.2)$ \\
\hline Total & $847(100.0)$ & $977(100.0)$ & $1824(100.0)$ \\
\hline \multicolumn{4}{|l|}{ Monthly income } \\
\hline$<100$ US\$/Month & $651(76.9)$ & $780(79.8)$ & $1431(78.5)$ \\
\hline 100-199 US\$/Month & $124(14.6)$ & $120(12.3)$ & $244(13.4)$ \\
\hline 200-299 US\$/Month & $47(5.5)$ & $55(5.6)$ & $102(5.6)$ \\
\hline$>300$ US\$/Month & $25(3.0)$ & $22(2.3)$ & $47(3.5)$ \\
\hline Total & $847(100.0)$ & $977(100.0)$ & $1824(100.0)$ \\
\hline \multicolumn{4}{|c|}{ Owning a modern house } \\
\hline No & 807 (95.3) & $951(74.9)$ & $1758(96.4)$ \\
\hline Yes & $40(4.7)$ & $26(25.1)$ & $66(3.6)$ \\
\hline Total & $847(100.0)$ & $977(100.0)$ & $1824(100.0)$ \\
\hline \multicolumn{4}{|l|}{ Owning a car } \\
\hline No & $799(94.3)$ & 908 (92.9) & $1707(93.6)$ \\
\hline Yes & $48(5.7)$ & $69(7.1)$ & $117(6.4)$ \\
\hline Total & $847(100.0)$ & $977(100.0)$ & $1824(100.0)$ \\
\hline
\end{tabular}

impairment were independent variables found to be more associated with physical disability. Furthermore, advance in age, female gender, arthritis, and depressive symptomatology were also significantly associated with functional limitation. As previously stated, studies on physical disability among elderly people in Nigeria is very scarce; therefore, comparison of findings in this study with studies elsewhere is limited by definition criteria, differences in the way disability was measured, and sample characteristics. Studies in which the scope of definition of disability was not wide; for example, in which disability is based on any level of difficulty in the performance of daily tasks, the prevalence of disability is expected to be high and probably higher than that from this study. In addition, studies that exclude institutionalized elderly persons, the range of disability will also be different. Institutional care of the elderly is very rare in Nigeria, and this study includes the entire range of functional limitations obtainable in rural population and thus excludes elderly in institutional care. Despite the scenario explained above, the rates of disability and functional limitation are comparable to levels reported among elderly persons in Malaysia [27].

Using the 10 items Barthel index, this study revealed that more than one fifth $(28.3 \%)$ of the elderly aged 60 years and above were dependent in at least one ADL. This finding is similar to that reported by previous studies $[27,28]$. However, a study in Singapore [29] found much lower disability prevalence than this study. Comparison with studies in other countries is difficult due to use of different ADL measurements; however, narrowing ADL disability to receiving help for at least one of five ADL items (eating, bathing, dressing, transferring, and toileting) or six ADL items (walking, eating, bathing, dressing, transferring, and toileting) allows reasonable comparison across some studies. Elderly women in this study have more functional disability than elderly men. Also, increase in age was found to be associated with increasing rates of disability. All these variables are often associated with the occurrence of disability as reported in the literature [30]. According to the six-item ADL index, the prevalence of physical disability for people aged 65 in this study was $21.4 \%$ (Table 2), which is moderately higher than the United States' National Long Term Care Survey [11], which is $13 \%$ ( $7.9 \%$ when age-standardized to the Nigerian population sample). However, the prevalence of six-item ADL disability among people age 60 years and above in the Caribbean [31], and among people age 75 years and above in Latin America and the Caribbean [23], appears to be similar to the prevalence rates in this study. Using the five-item ADL index, for people aged 65 years and above, the prevalence rates in this study is $15.6 \%$. This appears to be much higher when compared to the findings from developed countries [4], for example $6 \%$ in Canada $(3.2 \%$ when age standardized), $10 \%$ in France (5.5\% when age standardized), $14 \%$ in Italy $(7.3 \%$ when age standardized), and $11 \%$ in Sweden (5.5\% when age standardized) [11].

Disability prevalence rates in this study appear comparable to rates in other developing countries; for example, among people aged 65 and older, the prevalence of 5 items ADL disability in Malaysia [28] was $16 \%$ (14.8\% when age standardized) and $10 \%$ in Srilanka [32], (14.4\% when age standardized). The prevalence of disability among people aged 60 years and above was $12.1 \%$. This is almost similar to $12 \%$ in India [33] (9.3\% when age standardized) and $11 \%$ in Malaysia [26] (10.5\% when age standardized). However, the prevalence rate in this study is higher than $8 \%$ from 
TABLe 2: Prevalence of physical disability and functional limitation among elderly Nigerian $(n=1824)$.

\begin{tabular}{|c|c|c|c|c|c|}
\hline \multirow{3}{*}{ Variable } & \multirow{3}{*}{$N$} & \multicolumn{3}{|c|}{ Activities of daily living (ADL) dependence } & \multirow{3}{*}{$\begin{array}{c}\text { Functional limitation } \\
\text { RR }[95 \% \mathrm{CI}]\end{array}$} \\
\hline & & 10 items & 6 items & 5 items & \\
\hline & & $\mathrm{RR}[95 \% \mathrm{CI}]$ & $\mathrm{RR}[95 \% \mathrm{CI}]$ & $\mathrm{RR}[95 \% \mathrm{CI}]$ & \\
\hline \multicolumn{6}{|l|}{ Overall } \\
\hline$\geq 60$ & 1824 & $28.3(25.2,31.5)$ & $15.7(13.4,19.8)$ & $12.1(9.8,15.3)$ & $22.5(18.1,24.4)$ \\
\hline$\geq 65$ & 1221 & $39.1(35.4,44.5)$ & $21.4(17.8,25.6)$ & $15.6(12.6,19.2)$ & $28.2(25.3,32.8)$ \\
\hline$\geq 70$ & 824 & $45.5(42.8,52.8)$ & $27.3(22.4,31.9)$ & $22.2(17.7,25.4)$ & $38.0(32.5,43.7)$ \\
\hline$\geq 75$ & 317 & $52.8(43.8,61.7)$ & $34.6(28.3,45.1)$ & $26.6(19.4,35.3)$ & $51.5(43.7,60.5)$ \\
\hline \multicolumn{6}{|l|}{ Age group } \\
\hline $60-64$ & 603 & $11.7(7.5,18.3)$ & $10.3(6.4,17.30)$ & $8.1(4.2,14.36)$ & $12.4(7.2,19.2)$ \\
\hline $65-69$ & 497 & $72.3(52.2,89.5)$ & $31.3(19.7,50.5)$ & $22.3(11.5,33.7)$ & $38.4(32.3,55.2)$ \\
\hline $70-74$ & 407 & $78.4(64.2,94.3)$ & $37.7(27.3,53.2)$ & $29.9(20.2,44.5)$ & $48.8(37.6,66.4)$ \\
\hline$\geq 75$ & 317 & $98.9(85.3,111.7)$ & $59.9(52.3,86.2)$ & $50.4(35.5,65.7)$ & $98.3(40.1,56.6)$ \\
\hline \multicolumn{6}{|l|}{ Male } \\
\hline$\geq 60$ (overall) & 847 & $34.8(33.3,52.3)$ & $25.7(17.7,31.6)$ & $16.6(12.3,25.6)$ & $29.3(22.7,38.8)$ \\
\hline $60-64$ & 2651 & $5.3(7.1,29.5)$ & $10.8(5.3,20.3)$ & $9.7(3.5,22.4)$ & $9.8(3.3,11.2)$ \\
\hline $65-69$ & 242 & $37.7(23.0,64.2)$ & $15.4(7.5,32.6)$ & $17.4(6.8,26.8)$ & $27.7(15.7,26.8)$ \\
\hline $70-74$ & 201 & $63.4(40.7,85.3)$ & $32.4(15.7,59.3)$ & $23.2(11.4,52.6)$ & $34.7(17.6,63.2)$ \\
\hline$\geq 75$ & 139 & $73.4(51.1,99.6)$ & $41.3(21.7,69.8)$ & $30.0(14.4,59.8)$ & $72.2(43.9,52.7)$ \\
\hline \multicolumn{6}{|l|}{ Female } \\
\hline$\geq 60$ (overall) & 977 & $58.5(49.3,64.7)$ & $32.2(25.3,37.5)$ & $23.4(17.3,29.6)$ & $46.4(40.1,54.3)$ \\
\hline $60-64$ & 338 & $19.7(6.7,13.3)$ & $11.5(7.7,21.6)$ & $15.7(2.6,16.2)$ & $13.7(7.1,24.7)$ \\
\hline $65-69$ & 255 & $52.4(35.7,73.4)$ & $17.6(7.5,32.6)$ & $23.7(5.7,28.3)$ & $24.6(13.8,42.8)$ \\
\hline $70-74$ & 206 & $85.7(64.6,105.8)$ & $37.5(25.7,58.7)$ & $32.3(18.6,53.2)$ & $53.4(40.2,37.4)$ \\
\hline$\geq 75$ & 178 & $84.7(89.6,135.3)$ & $77.4(60.2,92.1)$ & $60.3(43.5,80.6)$ & $116.8(89.8,135.7)$ \\
\hline \multicolumn{6}{|c|}{ Monthly income (US\$/Month) } \\
\hline$<100$ & 1431 & $33.2(18.3,34.7)$ & $25.6(22.7,27.9)$ & $18.8(17.3,20.3)$ & $26.1(23.7,29.5)$ \\
\hline $100-199$ & 244 & $6.9(3.1,8.3)$ & $5.8(4.7,6.2)$ & $7.1(6.6,8.4)$ & $8.7(7.3,9.4)$ \\
\hline $200-299$ & 102 & $2.4(1.9,3.7)$ & $1.9(1.1,2.3)$ & $2.5(1.9,3.6)$ & $3.1(2.8,4.5)$ \\
\hline$>300$ & 47 & $0.6(0.2-0.9)$ & $0.7(1.2,1.8)$ & $0.6(0.2,1.4)$ & $1.4(0.8,1.9)$ \\
\hline
\end{tabular}

Shanghai, China [34]. Differences in criterion definition and sample profile may account for disparity between this finding and that of China. The following may be other possible reasons why Nigerian's disability prevalence rate is different from those reported from the developed countries: sample for this study was drawn from rural community, high illiteracy level $(85 \%)$, the low educational levels in elderly cohorts $(90.4 \%$ had no formal education or low education level), a figure higher than the developed country [35], and the prevailing sociodemographic differences between Nigeria and the wealthy industrialized nations. Since disability in $\mathrm{ADL}$ [36] is one of the main reasons for institutionalization in the developed nations, this may be another reason why prevalence of physical disability in elderly people in developed countries is lower compared with this finding.

The African tradition, particularly Nigerian tradition, dictates that elderly people should be taken care of by their family members. The institutional care of the elderly is very rare in Nigeria, thus majority of the elderly people in Nigeria live with their spouse or other family members.
Self-report or performance-based measures [4] are useful in assessing functional limitation. However, performance based measurements offers more information, because they help to identify important physical parameters involved in performing daily activity tasks [10]. Comparison of prevalence of functional limitation across studies is difficult due to differences in concept and measurement of functional limitation used. Using the Tinetti performance-oriented mobility assessment tool, the overall prevalence of functional limitation among Nigerian aged 75 years and above was $51.5 \%$ (Table 2). This is very close to a previous study [37] that reported $48 \%$ but much higher compared with that reported among the Italian [38] aged 75 years and above which was $21 \%$. This study shows a higher prevalence of physical disability and functional limitation among elderly women than elderly men in all age groups and the higher the age the wider the gender difference. Previous studies [39, 40] have also reported higher levels of physical disability and functional limitation in elderly women than elderly men. Cumulative effect of pregnancy and childbearing, poor/lack 
TABLE 3: Univariate analysis of variables associated with 10 items ADL dependence.

\begin{tabular}{|c|c|c|c|}
\hline Variables & $\begin{array}{c}\text { Physical disability } \\
\text { (present) frequency (\%) }\end{array}$ & $\begin{array}{c}\text { Physical disability } \\
\text { (absent) frequency (\%) }\end{array}$ & $\begin{array}{c}\text { Unadjusted prevalence ratio } \\
\text { PR }(95 \% \mathrm{CI})\end{array}$ \\
\hline \multicolumn{4}{|l|}{ Age group } \\
\hline $60-64$ & $31(9.5)$ & $296(90.5)$ & 1.0 (Reference) \\
\hline $65-69$ & $63(27.5)$ & $166(72.5)$ & $7.1(5.2,8.0)$ \\
\hline $70-74$ & $94(39.8)$ & $142(60.2)$ & $12.3(9.2,19.6)$ \\
\hline$\geq 75$ & $102(50.5)$ & $100(49.5)$ & $23.2(15.2,33.7)$ \\
\hline \multicolumn{4}{|l|}{$\operatorname{Sex}$} \\
\hline Male & $197(23.2)$ & $650(76.8)$ & 1.0 (Reference) \\
\hline Female & $306(31.3)$ & $671(68.7)$ & $3.9(2.8,7.4)$ \\
\hline \multicolumn{4}{|l|}{ Ethnic group } \\
\hline Kanuri & $402(26.2)$ & $1130(73.8)$ & 1.00 \\
\hline Fulani & $49(30.4)$ & $112(69.6)$ & $2.8(1.3,3.6)$ \\
\hline Hausa & $43(32.8)$ & $88(67.2)$ & $2.2(1.4,4.6)$ \\
\hline \multicolumn{4}{|l|}{ Education level } \\
\hline Tertiary education & $4(28.6)$ & $9(71.4)$ & 1.0 (Reference) \\
\hline Secondary & $45(27.9)$ & $116(72.1)$ & $1.6(1.2-3.8)$ \\
\hline Primary education & $115(22.4)$ & $399(77.6)$ & $3.2(2.6,4.4)$ \\
\hline No formal education & $320(36.6)$ & $1105(63.4)$ & $4.7(2.5,7.8)$ \\
\hline \multicolumn{4}{|l|}{ Marital status } \\
\hline Married & $308(26.4)$ & $858(73.62)$ & 1.0 (Reference) \\
\hline Widowed & $133(28.4)$ & $336(71.6)$ & $1.6(0.9,2.3)$ \\
\hline Divorced & $24(19.4)$ & $100(80.6)$ & $1.8(0.7,2.6)$ \\
\hline Single & $9(13.8)$ & $56(86.2)$ & $1.6(0.8,3.1)$ \\
\hline \multicolumn{4}{|l|}{ Living arrangements } \\
\hline Living with others & $399(24.8)$ & $1213(75.2)$ & 1.0 (Reference) \\
\hline Living alone & $63(29.7)$ & $149(60.3)$ & $3.2(2.7,10.6)$ \\
\hline \multicolumn{4}{|l|}{ Social support } \\
\hline Not at risk of isolation & $366(24.5)$ & $1277(75.5)$ & 1.0 (Reference) \\
\hline At risk of isolation & $115(34.7)$ & $320(65.3)$ & $1.8(1.5,3.8)$ \\
\hline \multicolumn{4}{|c|}{ Presence of chronic disease } \\
\hline None & $93(14.5)$ & $548(85.5)$ & 1.0 (Reference) \\
\hline One chronic disease & $260(26.1)$ & $737(73.9)$ & $6.2(7.7,13.8)$ \\
\hline More than one & $101(54.3)$ & $85(45.7)$ & $13.6(9.7,15.3)$ \\
\hline \multicolumn{4}{|l|}{ Diabetes } \\
\hline No & $40(20.8)$ & $152(79.2)$ & 1.0 (Reference) \\
\hline Yes & $145(44.1)$ & $184(55.9)$ & $5.7(4.9,12.3)$ \\
\hline \multicolumn{4}{|l|}{ Arthritis } \\
\hline No & $47(22.3)$ & $166(77.7)$ & 1.0 (Reference) \\
\hline Yes & $90(42.3)$ & $123(57.7)$ & $4.1(2.8,5.3)$ \\
\hline \multicolumn{4}{|l|}{ Stroke } \\
\hline No & $25(25.0)$ & $75(75.0)$ & 1.0 (Reference) \\
\hline Yes & $70(51.5)$ & $66(48.5)$ & $4.7(3.1,7.4)$ \\
\hline \multicolumn{4}{|l|}{ Malnutrition } \\
\hline No & $69(20.1)$ & $274(79.9)$ & 1.0 (Reference) \\
\hline Yes & $242(54.4)$ & $203(45.6)$ & $5.3(4.4,7.9)$ \\
\hline \multicolumn{4}{|c|}{ Depressive symptomatology } \\
\hline No & $313(22.5)$ & $1047(77.5)$ & 1.0 (Reference) \\
\hline Yes & $174(39.8)$ & $263(60.2)$ & $3.9(3.0,5.2)$ \\
\hline
\end{tabular}


Table 3: Continued.

\begin{tabular}{|c|c|c|c|}
\hline Variables & $\begin{array}{c}\text { Physical disability } \\
\text { (present) frequency (\%) }\end{array}$ & $\begin{array}{c}\text { Physical disability } \\
\text { (absent) frequency (\%) }\end{array}$ & $\begin{array}{c}\text { Unadjusted prevalence ratio } \\
\text { PR }(95 \% \mathrm{CI})\end{array}$ \\
\hline \multicolumn{4}{|l|}{ Presenting visual acuity } \\
\hline Normal & $260(26.1)$ & $737(73.9)$ & 1.0 (Reference) \\
\hline $\begin{array}{l}\text { Mild to moderate visual } \\
\text { impairment }\end{array}$ & $47(35.9)$ & $84(64.1)$ & $3.5(3.3,8.8)$ \\
\hline Blind & $240(34.5)$ & $456(65.5)$ & $4.8(3.5,8.7)$ \\
\hline \multicolumn{4}{|l|}{$B M I\left(K g / m^{2}\right)$} \\
\hline Normal & $184(24.7)$ & $574(75.3)$ & 1.0 (Reference) \\
\hline Underweight & $142(18.4)$ & $631(81.6)$ & $2.8(1.9,3.7)$ \\
\hline Overweight & $53(24.3)$ & $165(75.7)$ & $2.5(1.6,3.5)$ \\
\hline Obese & $17(22.7)$ & $58(77.3)$ & $2.2(1.4,2.9)$ \\
\hline
\end{tabular}

of education, and poor health care may be responsible for higher physical disability and functional limitation seen in elderly women.

Poor or lack of education may be associated with low income and poverty, poor standard of living, unhealthy lifestyle behavior, malnutrition, and less frequent use of health and medical care services [27]. This study showed that more elderly women $(80.1 \%)$ than elderly men (41.6) had no formal education; this is in conformity with the literature [41] that low socioeconomic status is associated with physical disability. Chronic disease like obesity was found to be commoner in elderly women than elderly men; this finding is similar to Malaysia study [27]. In addition, underweight is higher in elderly men than elderly women, this is also similar to Malaysia study [29]. Sedentary life style among elderly women and carbohydrate as the main food consumption could be the reason for overweight commoner in elderly women than elderly men.

In this study, the BMI values (20 to 24.9) associated with optimum physical function coincide with values associated with lowest risk of morbidity similar to previous studies in Chinese populations relating BMI to health outcomes [42, 43] and mobility decline [44]. This observation is not unexpected, given the close inverse relationship between walking speed and health-related outcomes in well-functioning older people $[45,46]$. The findings from this study emphasize yet another adverse effect of obesity in the elderly apart from increased risk of various diseases - that of functional limitation. For example, more than one-quarter $(28.3 \%)$ of the respondents signified interest for assistance in at least one of the 10 ADLs in the Barthel index (Table 2). The request for help for some of the activities of daily living suggests that muscle function may be adversely affected and may partly account for functional limitations. The association between grip strength and appendicular muscle mass emphasizes this point. In obese elderly people, an exercise component must be included in the treatment regimens to maintain or increase lean muscle mass and bone mineral density. Such regimens have been shown to result in a reduction in fat mass without changes in fat-free mass, increase physical performance, and improve quality of life [47].
Concerning the effect of ethnicity on prevalence of physical disability, this study showed that Hausas had the highest prevalence of self-reported physical disability followed by Fulanis and Kanuris. The observed differences among the ethnic groups may be attributed to different types of occupations as similarly expressed in a previous study [27]. In other words, hard labour is associated with physical disability due to increased risk of injury. This study revealed that Hausas and Fulanis are more commonly involved in very stressful and laborious manual occupations. Specifically, the Hausas and Fulanis are usually engaged in farming, tree felling, and truck pushing, while the Fulanis are usually engaged in nomadic activities. The Kanuris are mainly engaged in very less strenuous and laborious work. This study showed a significant association between functional limitations and advanced age, female gender, stroke, arthritis, and depressive symptomatology, and it is similar to findings from a previous study [27].

Living alone, poor social support, being overweight or underweight, presence of diabetes mellitus, stroke, and visual impairment were not associated with functional limitation. This finding is also similar to previous findings for advanced age [41], female gender [48], presence of arthritis [49] and depressive symptomatology $[49,50]$ being associated with functional limitation. This study is limited by involving only elderly people in rural community, excluding elders from institutions as well drawing of inferences between health-related variables and physical disability or functional limitation. Other limitations include study design (crosssectional design), which does not allow determination of direction of causality despite the presence of associations. In addition, the study design does not also include information on duration of disability thus making it difficult to confirm that some of the disabilities were or were not transient in nature. This study, however, has a number of strengths; this is one of the very few studies to assess the prevalence and correlates of performance-based functional limitation among elderly Nigerians. Validated measures of disability that conform with theories of aging were used, for example, in the Nagi model of disablement; functional limitation takes priority before (precedes) disability [51]. This study 
TABLE 4: Univariate analysis of variables associated with functional limitation variables.

\begin{tabular}{|c|c|c|c|}
\hline Variables & $\begin{array}{c}\text { Functional limitation present } \\
\text { Present frequency }(\%)\end{array}$ & $\begin{array}{c}\text { Functional limitation absent } \\
\text { Absent frequency }(\%)\end{array}$ & $\begin{array}{c}\text { Unadjusted prevalence ratio } \\
\text { PR }(95 \% \mathrm{CI})\end{array}$ \\
\hline \multicolumn{4}{|l|}{ Age group } \\
\hline $60-64$ & $38(6.3)$ & $565(93.7)$ & 1.0 (Reference) \\
\hline $65-69$ & $70(14.1)$ & 427 (85.9) & $5.5(4.2,6.8)$ \\
\hline $70-74$ & $105(25.8)$ & $302(74.2)$ & $10.3(6.6,14.7)$ \\
\hline$\geq 75$ & $150(47.3)$ & $167(52.7)$ & $18.5(11.1,33.7)$ \\
\hline \multicolumn{4}{|l|}{ Sex } \\
\hline Male & $130(15.3)$ & $717(84.7)$ & 1.0 (Reference) \\
\hline Female & $218(22.3)$ & $759(77.7)$ & $3.6(2.5,5.8)$ \\
\hline \multicolumn{4}{|l|}{ Ethnic group } \\
\hline Kanuri & $320(20.9)$ & $1312(79.1)$ & 1.0 (Reference) \\
\hline Fulani & $38(23.6)$ & $123(76.4)$ & $1.2(0.7,1.5)$ \\
\hline Hausa & $15(11.4)$ & $123(88.6)$ & $1.1(0.7,2.4)$ \\
\hline \multicolumn{4}{|l|}{ Education level } \\
\hline Tertiary education & $1(7.1)$ & $13(92.9)$ & 1.0 (Reference) \\
\hline Secondary education & $17(11.8)$ & $144(88.2)$ & $2.2(1.3,3.6)$ \\
\hline Primary education & $90(19.5)$ & $424(80.5)$ & $3.7(2.6,5.8)$ \\
\hline No formal education & $332(29.3)$ & $803(70.7)$ & $6.3(3.8,11.6)$ \\
\hline \multicolumn{4}{|l|}{ Marital status } \\
\hline Married & $240(20.60)$ & $926(79.4)$ & 1.0 (Reference) \\
\hline Widowed & $110(23.5)$ & $359(76.5)$ & $2.2(1.3,3.5)$ \\
\hline Single & $2(1.6)$ & $122(98.4)$ & $2.7(1.6,3.7)$ \\
\hline Divorced & $1(1.5)$ & $64(98.5)$ & $2.9(1.8,4.4)$ \\
\hline \multicolumn{4}{|l|}{ Living arrangements } \\
\hline Living with others & $340(21.1)$ & $1272(78.9)$ & 1.0 (Reference) \\
\hline Living alone & $37(17.5)$ & $175(82.5)$ & $2.3(1.4,2.7)$ \\
\hline \multicolumn{4}{|l|}{ Social support } \\
\hline Not at risk of isolation & $280(18.8)$ & $1213(81.3)$ & 1.0 (Reference) \\
\hline At risk of isolation & $88(26.6)$ & $243(73.4)$ & $2.8(1.9,4.5)$ \\
\hline \multicolumn{4}{|l|}{ Presence of chronic disease } \\
\hline None & $37(5.7)$ & $604(94.3)$ & 1.0 (Reference) \\
\hline One chronic disease & $230(23.1)$ & $767(76.9)$ & $9.6(5.7,12.4)$ \\
\hline More than one chronic-disease & $73(39.2)$ & $113(60.8)$ & $18.8(9.4,35.7)$ \\
\hline \multicolumn{4}{|l|}{ Diabetes } \\
\hline No & $160(17.2)$ & $766(82.8)$ & 1.0 (Reference) \\
\hline Yes & $337(37.5)$ & $561(62.5)$ & $9.4(8.7,12.8)$ \\
\hline \multicolumn{4}{|l|}{ Arthritis } \\
\hline No & $171(14.5)$ & $1001(85.5)$ & 1.0 (Reference) \\
\hline Yes & $260(39.9)$ & $392(60.1)$ & $8.9(6.8,11.5)$ \\
\hline \multicolumn{4}{|l|}{ Stroke } \\
\hline No & $255(20.4)$ & $993(79.6)$ & 1.0 (Reference) \\
\hline Yes & $251(43.6)$ & $325(56.4)$ & $5.8(3.9,7.2)$ \\
\hline \multicolumn{4}{|l|}{ Depressive symptomatology } \\
\hline No & $211(15.2)$ & $1176(84.8)$ & 1.0 (Reference) 1387 \\
\hline Yes & $163(37.3)$ & $274(62.7)$ & $9.9(7.4,14.5)$ \\
\hline \multicolumn{4}{|l|}{ Presenting visual acuity } \\
\hline Normal & $252(16.8)$ & $1250(83.2)$ & 1.0 (Reference) \\
\hline Mild to moderate-Visual impairment & $70(31.7)$ & $151(68.3)$ & $1.8(1.2,2.9)$ \\
\hline Blind & $40(33.1)$ & $81(66.9)$ & $5.6(3.7,8.8)$ \\
\hline
\end{tabular}


TABLE 4: Continued.

\begin{tabular}{lccc}
\hline Variables & $\begin{array}{c}\text { Functional limitation present } \\
\text { Present frequency (\%) }\end{array}$ & $\begin{array}{c}\text { Functional limitation absent } \\
\text { Absent frequency }(\%)\end{array}$ & $\begin{array}{c}\text { Unadjusted prevalence ratio } \\
\text { PR (95\% CI) }\end{array}$ \\
\hline$B M I\left(K g / \mathrm{m}^{2}\right)$ & & & \\
Normal & $158(20.8)$ & $600(78.1)$ & 1.0 (Reference) \\
Underweight & $198(25.6)$ & $575(74.4)$ & $2.4(1.9,4.2)$ \\
Overweight & $44(20.2)$ & $174(79.8)$ & $2.6(2.2,4.7)$ \\
Obese & $13(17.3)$ & $62(82.7)$ & $2.7(2.5,5.3)$ \\
\hline
\end{tabular}

TABLE 5: Adjusted prevalence ratios for associations between sociodemographic and health related variables and poor physical function among elderly rural Nigerian.

\begin{tabular}{lcc}
\hline Variables & $\begin{array}{c}\text { Physical disability* } \\
\text { as-dependent variable }(n=1824)\end{array}$ & $\begin{array}{c}\text { Functional limitation } \\
\text { as-dependent variable }(n=1824)\end{array}$ \\
\hline Age group & 1.0 & 1.0 \\
$60-64$ & $3.1(2.2,3.6)$ & $5.2(3.7,7.8)$ \\
$65-69$ & $14.4(10.2,17.6)$ & $7.5(5.4,11.2)$ \\
$70-74$ & $22.2(14.5,36.8)$ & $10.5(5.4,16.4)$ \\
$\geq 75$ & $3.6(1.5,7.4)$ & $9.3(3.7,18.3)$ \\
Female & & \\
Self reported chronic medical condition ${ }^{* *}$ & $6.1(4.3,7.1)$ & $3.8(3.1,5.2)$ \\
Diabetes mellitus & $4.8(3.7,7.9)$ & $3.6(2.2,5.4)$ \\
Stroke & $3.7(2.6,4.6)$ & $5.2(3.5,6.8)$ \\
Arthritis & $4.2(3.3,5.9)$ & $6.4(4.7,9.2)$ \\
Presence of depressive-symtomatology ${ }^{* *}$ & & \\
Presenting visual acuity & 1.0 & 1.0 \\
Normal & $5.2(3.4,7.3)$ & $3.8(2.5,6.7)$ \\
Mild-to-moderate visual impairment & $6.6(3.6,11.9)$ & $4.7(2.2,10.4)$ \\
Blind & & \\
\hline
\end{tabular}

also revealed that severe malnutrition was associated with disability. Relationship between malnutrition and disability has also been reported by a previous study in rural Malawi, where Chilima and Ismail observed a relationship between undernutrition and handgrip strength, psychomotor speed and coordination, and mobility and ability to carry out activities of daily living independently [52].

\section{Conclusion}

Disability in old age is an important indicator of any community population health, as elderly people usually have more than one illness, and the functional impacts of combined conditions provide a better measure of health than do diagnostic categories. In addition, in developing countries, access to physicians is limited, and most ailments in the elderly are associated with old age. This study has shown that the overall pattern of disability in Nigeria has the relationships similar with studies elsewhere. Of particular note is that physical disability and functional limitation is common in Nigerian elderly. Though the prevalent rates of physical disability and functional limitation is higher than that obtainable in developed countries but similar and comparable to partner developing countries. More importantly, elderly women, especially those with advanced age, chronic diseases, depressive symptomatology, and visual impairments showed greater risk of disability and functional limitation compared with elderly men. This finding is indispensable when considering those to focus for appropriate prevention and intervention strategies like physical exercise, health education, and home visits of high-risk individuals in community-dwelling Nigerians.

\section{References}

[1] A. Kinsella, "Demographic aspects," in Epidemiology in Old Age, S. Ebrahim and A. Kalache, Eds., pp. 32-40, BMJ, London, UK, 1996.

[2] L. M. Verbrugge and A. M. Jette, "The disablement process," Social Science and Medicine, vol. 38, no. 1, pp. 1-14, 1994.

[3] T. M. Gill, M. M. Desai, E. A. Gahbauer, T. R. Holford, and C. S. Williams, "Restricted activity among communityliving older persons: incidence, precipitants, and health care utilization," Annals of Internal Medicine, vol. 135, no. 5, pp. 313-321, 2001. 
[4] L. P. Fried and J. M. Guralnik, "Disability in older adults: evidence regarding significance, etiology and risk," Journal of the American Geriatrics Society, vol. 45, no. 1, pp. 92-100, 1997.

[5] The Medical Research Council Cognitive Function and Ageing Study (MRC CFAS), "Cognitive function and dementia in six areas of England and Wales: the distribution of MMSE and prevalence of GMS organicity level in the MRC CFA Study," Psychological Medicine, vol. 28, no. 2, pp. 319-335, 1998.

[6] J. Wiener, "Long term care reform: an international perspective," in Health Care Reform: The Will to Change, Health Policy Studies Number 8, Organization for Economic Cooperation and Development, Paris, France, 1996.

[7] World Health Organization, "Health futures," 1999, http:// www.who.int/hpr/expo.

[8] World Health Organization, World Health Report 2004: Changing History, World Health Organization, Geneva, Switzerland, 2004.

[9] Encyclopedia of Death and Dying, "Life expectancy," 2011, http://www.deathreference.com/Ke-Ma/Life-Expectancy.html.

[10] J. M. Guralnik and L. Ferrucci, "Assessing the building blocks of function: utilizing measures of functional limitation," American Journal of Preventive Medicine, vol. 25, no. 3, supplement 2, pp. 112-121, 2003.

[11] G. Lafortune, G. Balestat, and The Disability Study Expert Group Members, Trends in Severe Disability Among Elderly People: Assessing the Evidence in 12 OECD Countries and the Future Implications, OECD Health Working Papers, no 26, OECD Publishing, 2007.

[12] S. M. McCurry, L. E. Gibbons, G. E. Bond et al., "Older adults and functional decline: a cross-cultural comparison," International Psychogeriatrics, vol. 14, no. 2, pp. 161-179, 2002.

[13] Y. Ostchega, T. B. Harris, R. Hirsch, V. L. Parsons, and R. Kington, "The prevalence of functional limitations and disability in older persons in the US: data from the national health and nutrition examination survey III," Journal of the American Geriatrics Society, vol. 48, no. 9, pp. 1132-1135, 2000.

[14] M. I. Parahyba, R. Veras, and D. Melzer, "Disability among elderly women in BrazilIncapacidade funcional entre as mulheres idosas no Brasil," Revista de Saude Publica, vol. 39, no. 3, pp. 383-391, 2005.

[15] United Nations Population Division, Population, Health, and Human Well-Being-Nigeria, EarthTrends, 2003.

[16] J. A. Yesavage, T. L. Brink, T. L. Rose et al., "Development and validation of a geriatric depression screening scale: a preliminary report," Journal of Psychiatric Research, vol. 17, no. 1, pp. 37-49, 1982.

[17] E. H. Kua and S. M. Ko, "A questionnaire to screen for cognitive impairment among elderly people in developing countries," Acta Psychiatrica Scandinavica, vol. 85, no. 2, pp. 119-122, 1992.

[18] N. G. Congdon, D. S. Friedman, and T. Lietman, "Important causes of visual impairment in the world today," Journal of the American Medical Association, vol. 290, no. 15, pp. 2057-2060, 2003.

[19] M. E. Tinetti, "Performance-orientated assessment of mobility problems in elderly patients," Journal of the American Geriatrics Society, vol. 34, no. 2, pp. 119-126, 1986.

[20] L. Ferrucci, C. Koh, S. Bandinelli, and J. M. Guralnik, "Disability, functional status and activities of daily living," in Encyclopedia of Gerontology, J. E. Birren, Ed., vol. 1, pp. 427-436, Amsterdam: Academic Press, Boston, Mass, USA, 2nd edition, 2007.
[21] D. T. Wade and C. Collin, "The barthel ADL Index: a standard measure of physical disability?" International Disability Studies, vol. 10, no. 2, pp. 64-67, 1988.

[22] S. Katz, A. B. Ford, R. W. Moskowitz, B. A. Jackson, and M. W. Jaffe, "Studies of illness in the aged: the index of ADL: a standardized measure of biological and psychosocial function," Journal of the American Medical Association, vol. 185, pp. 914-919, 1963.

[23] A. Rose, A. Hennis, and I. Hambleton, "Sex and the city: differences in disease and disability-free life years, and active community participation of elderly men and women in 7 cities in Latin America and the Caribbean," BMC Public Health, vol. 8, no. 1, article 127, 2008.

[24] K. Shantibala, B. Naorem, J. Ak, B. Ak, D. E Vijaya, and S. Y Manihar, "Disability in ADL among the elderly in an urban area of Manipur," Indian Journal of Physical Medicine and Rehabilitation, vol. 18, no. 2, pp. 41-43, 2007.

[25] A. Barros and V. N. Hirakata, "Alternatives for logistic regression in cross-sectional studies: an empirical comparison of models that directly estimate the prevalence ratio," BMC Medical Research Methodology, vol. 3, article 21, pp. 1-13, 2003.

[26] D. Spiegelman and E. Hertzmark, "Easy SAS calculations for risk or prevalence ratios and differences," American Journal of Epidemiology, vol. 162, no. 3, pp. 199-200, 2005.

[27] N. N. Hairi, A. Bulgiba, R. G. Cumming II, V. Naganathan, and I. Mudla, "Prevalence and correlates of physical disability and functional limitation among community dwelling older people in rural Malaysia, a middle income country," $B M C$ Public Health, vol. 10, Article ID 492, 2010.

[28] M. Sherina, L. Rampal, M. Aini, and H. Norhidayati, "The prevalence of depression among elderly in an urban area of Selangor, Malaysia," The International Medical Journal, vol. 4, no. 2, pp. 57-63, 2005.

[29] T.-P. Ng, M. Niti, P.-C. Chiam, and E.-H. Kua, "Prevalence and correlates of functional disability in multiethnic elderly Singaporeans," Journal of the American Geriatrics Society, vol. 54, no. 1, pp. 21-29, 2006.

[30] A. E. Stuck, J. M. Walthert, T. Nikolaus, C. J. Bula, C. Hohmann, and J. C. Beck, "Risk factors for functional status decline in community-living elderly people: a systematic literature review," Social Science and Medicine, vol. 48, no. 4, pp. $445-469,1999$.

[31] C. A. Reyes-Ortiz, G. V. Ostir, M. Pelaez, and K. J. Ottenbacher, "Cross-national comparison of disability in latin american and caribbean persons aged 75 and older," Archives of Gerontology and Geriatrics, vol. 42, no. 1, pp. 21-33, 2006.

[32] D. B. Nugegoda and S. Balasuriya, "Health and social status of an elderly urban population in Sri Lanka," Social Science and Medicine, vol. 40, no. 4, pp. 437-442, 1995.

[33] Z. Tang, H. X. Wang, C. Meng et al., "The prevalence of functional disability in activities of daily living and instrumental activities of daily living among elderly Beijing Chinese," Archives of Gerontology and Geriatrics, vol. 29, no. 2, pp. 115-125, 1999.

[34] P. Chen, E. Yu, M. Zhang, W. T. Liu, R. Hill, and R. Katzman, "ADL dependence and medical conditions in chinese older persons: a population-based survey in Shanghai, China," Journal of the American Geriatrics Society, vol. 43, no. 4, pp. 378-383, 1995.

[35] Federal Interagency Forum on Aging-Related Statistics, Older Americans 2008: Key Indicators of Well-Being, U.S. Government Printing. 
[36] J. M. Guralnik, L. P. Fried, and M. E. Salive, "Disability as a public health outcome in the aging population," Annual Review of Public Health, vol. 17, pp. 25-46, 1996.

[37] L. Bergamini, M. Burgoni, G. Federzoni et al., "Multidimensional evaluation of home-dwelling elderly: the impact of medical and social factors on health status indices," Archives of Gerontology and Geriatrics, vol. 44, supplement 1, pp. 75-81, 2007.

[38] L. Dalle Carbonare, S. Maggi, M. Noale et al., "Physical disability and depressive symptomatology in an elderly population: a complex relationship: the italian longitudinal study on aging (ILSA)," American Journal of Geriatric Psychiatry, vol. 17, no. 2, pp. 144-154, 2009.

[39] U. Tas, A. Verhagen, S. Bierma-Zeinstra et al., "Incidence and risk factors of disability in the elderly: the Rotterdam study," Preventive Medicine, vol. 44, no. 3, pp. 272-278, 2007.

[40] U. Tas, A. P. Verhagen, S. Bierma-Zeinstra, E. Odding, and B. Koes, "Prognostic factors of disability in older people: a systematic review," British Journal of General Practice, vol. 57, no. 537, pp. 319-323, 2007.

[41] A. Koster, H. Bosma, M. Broese Van Groenou et al., "Explanations of socioeconomic differences in changes in physical function in older adults: results from the longitudinal aging study amsterdam," BMC Public Health, vol. 6, no. 1, article 244, 2006.

[42] J. Woo, S. C. Ho, A. L. M. Yu, and A. Sham, "Is waist circumference a useful measure in predicting health outcomes in the elderly?" International Journal of Obesity and Related Metabolic Disorders, vol. 26, no. 10, pp. 1349-1355, 2002.

[43] S. C. Ho, J. Woo, S. S. G. Chan, Y. K. Yuen, and A. Sham, "Risk factors and prevention of falls in the Chinese elderly population," The Journals of Gerontology, vol. 51, pp. M195M198, 1996.

[44] S. C. Ho, J. Woo, Y. K. Yuen, A. Sham, and S. G. Chan, "Predictors of mobility decline: the Hong Kong old-old study," The Journals of Gerontology, vol. 52, pp. M356-M362, 1997.

[45] M. Cesari, S. B. Kritchevsky, B. W. H. J. Penninx et al., "Prognostic value of usual gait speed in well-functioning older people-results from the health, aging and body composition study," Journal of the American Geriatrics Society, vol. 53, no. 10, pp. 1675-1680, 2005.

[46] J. Woo, S. C. Ho, and A. L. M. Yu, "Walking speed and stride length predicts 36 months dependency, mortality, and institutionalization in Chinese aged 70 and older," Journal of the American Geriatrics Society, vol. 47, no. 10, pp. 1257-1260, 1999.

[47] D. T. Villareal, M. Banks, D. R. Sinacore, C. Siener, and S. Klein, "Effect of weight loss and exercise on frailty in obese older adults," Archives of Internal Medicine, vol. 166, no. 8, pp. 860-866, 2006.

[48] L. Dalle Carbonare, S. Maggi, M. Noale et al., "Physical disability and depressive symptomatology in an elderly population: a complex relationship. the italian longitudinal study on aging (ILSA)," American Journal of Geriatric Psychiatry, vol. 17, no. 2, pp. 144-154, 2009.

[49] D. Melzer and M. I. Parahyba, "Socio-demographic correlates of mobility disability in older Brazilians: results of the first national survey," Age and Ageing, vol. 33, no. 3, pp. 253-259, 2004.

[50] D. Melzer, E. Gardener, and J. M. Guralnik, "Mobility disability in the middle-aged: cross-sectional associations in the English longitudinal study of ageing," Age and Ageing, vol. 34, no. 6, pp. 594-602, 2005.
[51] S. Nagi, "An epidemiology of disability among adults in the United States," Milbank Memorial Fund Quarterly, Health and Society, vol. 54, no. 4, pp. 439-467, 1976.

[52] D. M. Chilima and S. J. Ismail, "Nutrition and handgrip strength of older adults in rural Malawi," Public Health Nutrition, vol. 4, no. 1, pp. 11-17, 2001. 


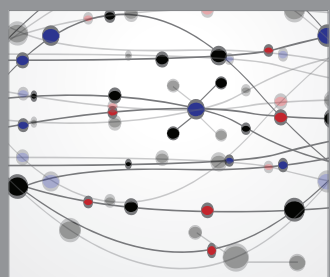

The Scientific World Journal
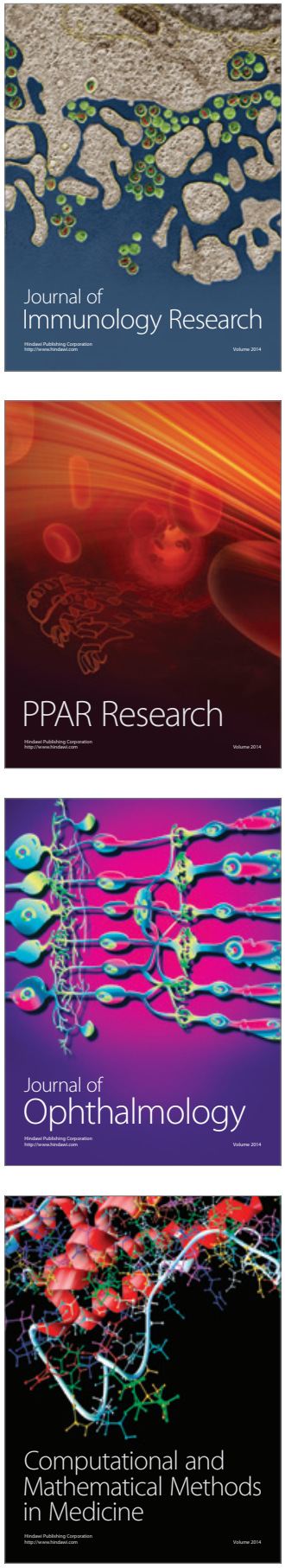

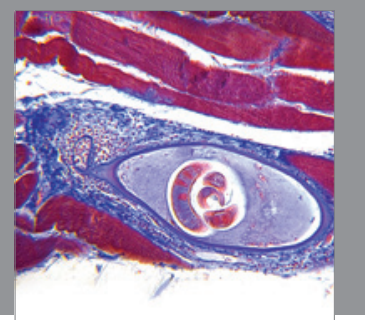

Gastroenterology

Research and Practice
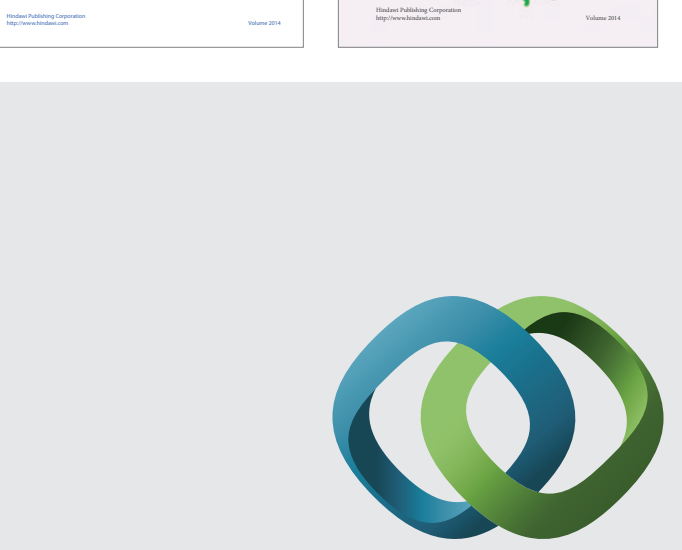

\section{Hindawi}

Submit your manuscripts at

http://www.hindawi.com
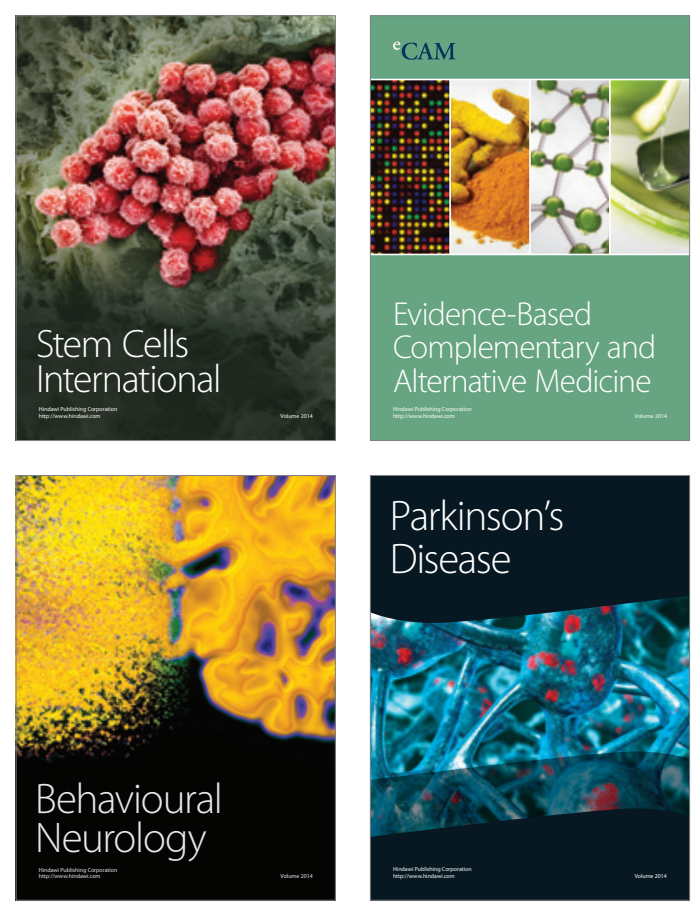

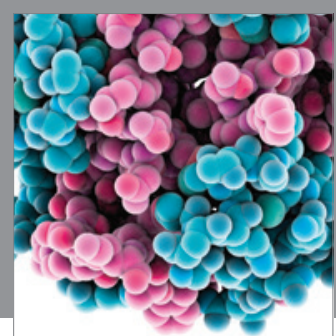

Journal of
Diabetes Research

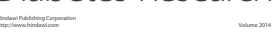

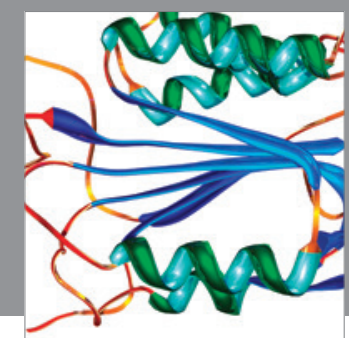

Disease Markers
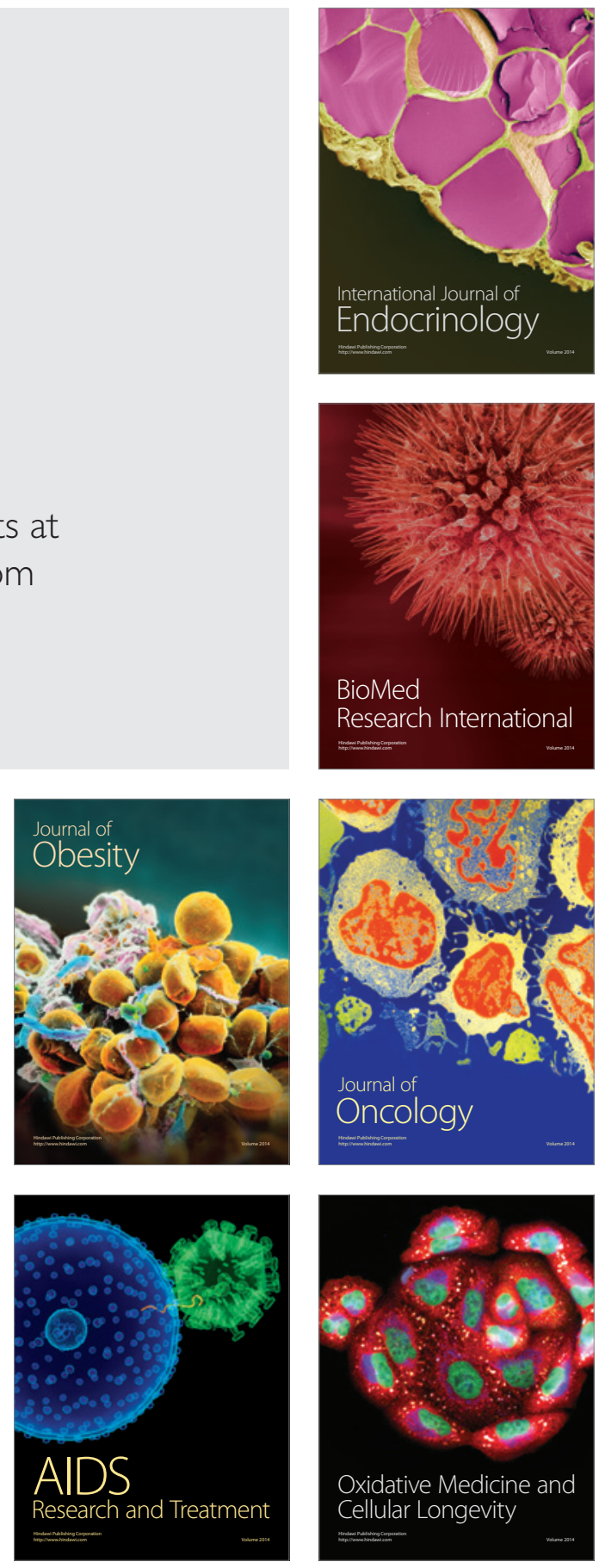